\title{
Small anion-assisted electrochemical potential splitting in a new series of bistriarylamine derivatives: organic mixed valency across a urea bridge and zwitterionization
}

\author{
Keishiro Tahara*1,2, Tetsufumi Nakakita ${ }^{2}$, Alyona A. Starikova ${ }^{3}$, Takashi lkeda $^{1}$, \\ Masaaki $\mathrm{Abe}^{1}$ and Jun-ichi Kikuchi ${ }^{* 2}$
}

\author{
Full Research Paper

\section{Address:} \\ 1Department of Material Science, Graduate School of Material \\ Science, University of Hyogo, 3-2-1, Kouto, Kamigori, Ako, Hyogo \\ 678-1297, Japan, ${ }^{2}$ Graduate School of Materials Science, Nara \\ Institute of Science and Technology, 8916-5, Takayama, Ikoma, Nara \\ 630-0192, Japan and ${ }^{3}$ Institute of Physical and Organic Chemistry, \\ Southern Federal University, pr. Stachki 194/2, Rostov on Don, \\ 344090, Russian Federation

\section{Email:} \\ Keishiro Tahara* - taharak@sci.u-hyogo.ac.jp; Jun-ichi Kikuchi” - \\ jkikuchi@ms.naist.jp \\ ${ }^{*}$ Corresponding author

\section{Keywords:} \\ anion binding; electrochemistry; hydrogen bonding; triarylamine; urea; \\ zwitterionic mixed valency \\ Beilstein J. Org. Chem. 2019, 15, 2277-2286. \\ doi: $10.3762 /$ bjoc. 15.220 \\ Received: 04 June 2019 \\ Accepted: 05 September 2019 \\ Published: 24 September 2019 \\ Associate Editor: J. A. Murphy \\ (c) 2019 Tahara et al.; licensee Beilstein-Institut. \\ License and terms: see end of document.
}

\begin{abstract}
We report the synthesis of a new bistriarylamine series having a urea bridge and investigate its mixed-valence (MV) states by electrochemical and spectroelectrochemical methods. We found that the supporting electrolytes had unusual effects on potential splitting during electrochemical behavior, in which a smaller counteranion thermodynamically stabilized a MV cation more substantially than did a bulky one. The effects contrary to those reported in conventional MV systems were explained by zwitterionization through hydrogen bonding between the urea bridge and the counteranions, increasing the electronic interactions between two triarylamino units. Furthermore, we clarified the intervalence charge transfer characteristics of the zwitterionic MV state.
\end{abstract}

\section{Introduction}

Mixed-valence (MV) compounds have received increasing attention from the viewpoint of fundamental research on intramolecular electron transfer phenomena and application in molecular devices [1-5]. The radical cations of bistriarylamine derivatives bis $\left(\mathrm{NAr}_{3}\right)$ are well-known $\mathrm{MV}$ compounds having $\pi$-conjugated bridges (where $\mathrm{NAr}_{3}=$ triarylamine) [6-18]. These studies focused on evaluating the intervalence charge transfer (IVCT) transition near-infrared (NIR) absorption from $\mathrm{NAr}_{3}$ to $\mathrm{NAr}_{3}{ }^{\bullet+}$ units [1-5]. The IVCT absorptions of MV compounds are generally more pronounced in organic species 
$[19,20]$ than in their inorganic counterparts. The strong IVCT characteristics of the bis $\left(\mathrm{NAr}_{3}\right)^{\bullet+}$ radical cations are well documented due to their good availability through common $\mathrm{N}-\mathrm{C}$ bond-forming reactions and the stability of the $\mathrm{NAr}_{3}{ }^{\cdot+}$ unit [6-18]. Photoswitchable mixed valency has recently been demonstrated with bis $\left(\mathrm{NAr}_{3}\right)^{\bullet+}$ radical cations having dithienylethene bridges [21,22]. This was achieved by a regulation of the $\pi$-conjugation length through photoinduced formation/dissociation of $\sigma$ bonds in the bridge, which was accomplished with changeovers from a localized system (class I) to a moderately delocalized one (class II), as well as and from moderately delocalized one to a highly delocalized one (class III) [1-5]. However, attempts to change the MV characteristics by manipulating the bridge moieties through intermolecular interactions have not been reported for bis $\left(\mathrm{NAr}_{3}\right)$ derivatives.

Redox stimuli are a promising trigger to directly change the charge distributions of molecules and assemblies, potentially allowing tuning of the strength of non-covalent interactions, including hydrogen bonds (H-bonds) [23-26]. In this context, a number of redox-active compounds bearing $\mathrm{H}$-bond donors and acceptors were investigated to realize electrochemically controlled H-bonding [23-36]. Especially, oxidation-active ureas are an important class of such compounds $[25,26]$. In the neutral state, ureas can provide two $\mathrm{NH}$ protons for multiple H-bonding, as often used for anion recognition [27-29]. In the oxidized state, the enhanced acidity of $\mathrm{NH}$ protons can increase the strength of $\mathrm{H}$-bonds and give them more dynamic properties, which can be useful for refined designs of supramolecular systems [30] and proton-coupled electron-transfer systems [3140]. In contrast to the vast majority of oxidation-active ureas, those having two redox centers at both ends have not received attention except for 1,3-bis(ferrocenyl)urea FcFc [41,42], a cyclometalated diruthenium complex [43], and bis $\left(\mathrm{NAr}_{3}\right)$ counterparts, including 1a (Figure 1) [44]. The electrochemically control of $\mathrm{H}$-bonding would have a dramatic impact on the field of mixed valency, which is striving to utilize charge delocalization for molecular devices. However, there is a lack of basic knowledge about the influence of an excess of supporting electrolytes on the thermodynamic stability of urea-bridged MV species. In this study, we report the synthesis and characterization of a new series of urea-bridged bis $\left(\mathrm{NAr}_{3}\right)$ derivatives $\mathbf{1}$ and investigate their MV states by electrochemical and spectroelectrochemical methods. We found that the supporting electrolytes have unusual effects on the thermodynamic stability of MV ions in terms of bulkiness of the counterion. Furthermore, we clarified the IVCT characteristics of the zwitterionic organic MV state.

\section{Results and Discussion Synthesis and characterization of 1 in the neutral form}

The target compounds $\mathbf{1}$ with different substituents $\mathrm{R}$ at the para-position of the benzene adjacent to the nitrogen centers were synthesized to tune the oxidation potential of the nitrogen centers (Figure 1). According to a previously reported method for the synthesis of ureas [45], symmetric ureas 1 were synthesized from the corresponding amines with triphosgene. An unsymmetrical reference urea having a $\mathrm{NAr}_{3}$ moiety, $\mathbf{P h 1 b}$, was also synthesized. The new compound series was characterized by ${ }^{1} \mathrm{H}$ NMR and EIMS (Figures S1-S4 in Supporting Information File 1). In the DFT-optimized structures of $\mathbf{1}$, the ureylene moiety and the phenyl groups on both sides are almost coplanar with $\mathrm{N} \cdots \mathrm{N}$ distances between the $\mathrm{NAr}_{3}$ moieties of more than $13 \AA$ (Figure S5 and Table S1 in Supporting Information File 1). Further investigations were not performed for 1c because the solubility of this compound in aprotic solvents including $\mathrm{CH}_{2} \mathrm{Cl}_{2}$ were extremely low.

The electrochemical behavior of $\mathbf{1 a}$ and $\mathbf{1 b}$ having two chemically equivalent $\mathrm{NAr}_{3}$ units was investigated by cyclic voltammetry and differential pulse voltammetry. Interestingly, two reversible waves were observed for $\mathbf{1 b}$ in $\mathrm{CH}_{2} \mathrm{Cl}_{2}$ containing $0.10 \mathrm{M} n-\mathrm{Bu}_{4} \mathrm{NPF}_{6}$ (Figure 2, bottom, and Table 1 and Table S3 in Supporting Information File 1). In contrast, the reference urea $\mathbf{P h 1 b}$ exhibited one reversible wave correspond-<smiles>[R]c1ccc(N(c2ccc([R])cc2)c2ccc(NC(=O)Nc3ccc(N(c4ccc([R])cc4)c4ccc([R])cc4)cc3)cc2)cc1</smiles><smiles>Cc1ccc(N(c2ccc(C)cc2)c2ccc(NC(=O)Nc3ccccc3)cc2)cc1</smiles>

Ph1b 

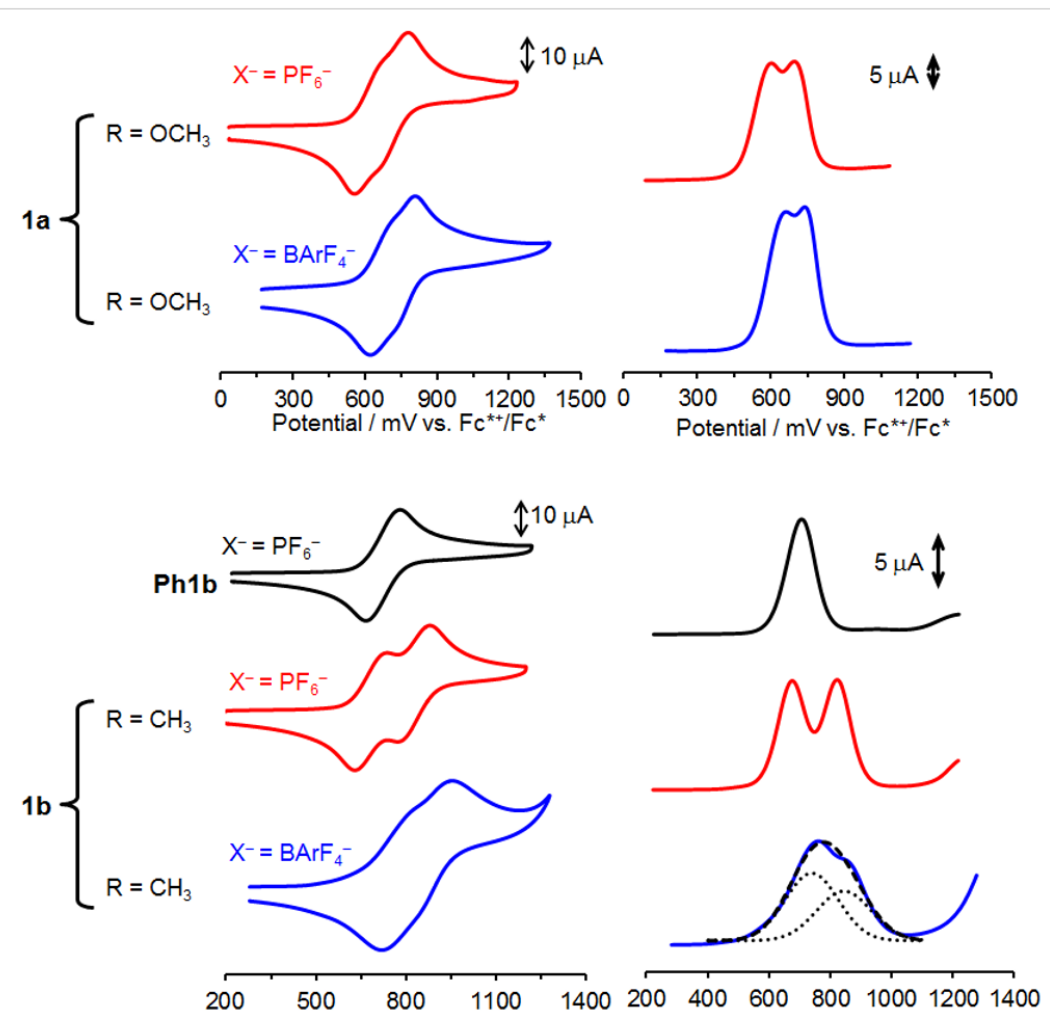

Figure 2: Cyclic voltammograms (left) and differential pulse voltammograms (right) of (top) $\mathbf{1 a}$, (middle) $\mathbf{P h} \mathbf{1 b}$, and (bottom) $\mathbf{1 b}$ (1.0 mM) in $\mathrm{CH}_{2} \mathrm{Cl}$ containing $n-\mathrm{Bu}_{4} \mathrm{NX}(0.10 \mathrm{M})$. Scan rate: $100 \mathrm{mV} \mathrm{s}^{-1}$. For the differential pulse voltammogram of $1 \mathbf{b}$ with $\mathrm{BArF}_{4^{-}}$, Gaussian deconvolution (black dotted line) and the sum (black dashed line) were also shown.

Table 1: Electrochemical data for 1 in $\mathrm{CH}_{2} \mathrm{Cl}_{2} \cdot{ }^{\mathrm{a}}$

\begin{tabular}{llllll} 
Compounds & $\mathrm{X}^{-}$ & $E_{1 / 2}{ }^{1}$ & $E_{1 / 2}{ }^{2}$ & $\Delta E_{1 / 2}{ }^{\mathrm{b}}$ & $K_{\mathrm{c}^{\mathrm{c}}}$ \\
\hline 1a & $\mathrm{PF}_{6}{ }^{-}$ & 606 & 700 & 94 & 39 \\
& $\mathrm{BArF}_{4}{ }^{-}$ & 674 & 740 & 66 & 13 \\
1b & $\mathrm{PF}_{6}{ }^{-}$ & 696 & 840 & 144 & 272 \\
& $\mathrm{BArF}_{4}^{-}$ & 784 & 891 & 107 & 64 \\
Ph1b & $\mathrm{PF}_{6}^{-}$ & 724 & - & - & - \\
\hline
\end{tabular}

aln the presence of $0.1 \mathrm{Mn} n-\mathrm{Bu}_{4} \mathrm{NX}$. Potentials in $\mathrm{mV}$ vs. $\mathrm{Fc}^{\star+} / \mathrm{Fc}^{*}$ $\left(\mathrm{FC}^{\star}{ }^{*}=\right.$ decamethylferrocene $) .{ }^{\mathrm{b}} \Delta E_{1 / 2}=$ potential difference between two redox processes. ${ }^{\circ}$ Comproportionation constants obtained from $K_{\mathrm{C}}=\exp \left(\Delta E_{1 / 2} F / R T\right)$.

ing to the oxidation of the $\mathrm{NAr}_{3}$ unit, indicating that further oxidation of $\mathbf{P h 1} \mathbf{b}^{+}$to the $\mathrm{NAr}_{3}{ }^{2+}$ species did not proceed in the potential range applied. The $E_{1 / 2}{ }^{1}$ and $E_{1 / 2}{ }^{2}$ values for $\mathbf{1 b}$ are $28 \mathrm{mV}$ lower and $116 \mathrm{mV}$ higher, respectively, than the redox potential for Ph1b, affording a large split in the redox potentials of $144 \mathrm{mV}$. These results clearly indicate the consecutive oxidation of the $\mathrm{NAr}_{3}$ units in $\mathbf{1} \mathbf{b}$ and the formation of the cationic and dicationic species, $\mathbf{1} \mathbf{b}^{+}$and $\mathbf{1} \mathbf{b}^{\mathbf{2 +}}$ (Equation 1). It is notable that the organic MV species $\mathbf{1} \mathbf{b}^{+}$has a relatively large comproportionation constant $\left(K_{\mathrm{c}}\right)$, in the order of $10^{2}$ in the polar medium $\left(\mathrm{CH}_{2} \mathrm{Cl}_{2} / n-\mathrm{Bu}_{4} \mathrm{NPF}_{6}\right)$, whereas small potential splitting values were often reported for general MV compounds [46-52]. The $E_{1 / 2}{ }^{1}$ value for $\mathbf{1 a}$ decreases by $90 \mathrm{mV}$ compared with that for $\mathbf{1 b}$. This substituent effect on the oxidation potential is typical for the reported $\mathrm{NAr}_{3}$ system [53]. Because the electron-donating group of the $\mathrm{NAr}_{3}$ unit destabilizes the MV state, the potential splitting for $\mathbf{1 a}$ is $50 \mathrm{mV}$ smaller than that for 1b (Figure 2, top). Similar substituent effects were previously reported for bis $\left(\mathrm{NAr}_{3}\right)$ derivatives having $\pi$-conjugated bridges $[8,9]$. Judging from the long $\mathrm{N} \cdots \mathrm{N}$ distances (e.g., $13.16 \AA$ for $\mathbf{1 b}^{+}$) in the DFT-optimized structure (Figure S5 in Supporting Information File 1), the through-space electrostatic interactions between the $\mathrm{NAr}_{3}$ units could not contribute to the relatively large thermodynamic stability of $\mathbf{1 a}^{+}$and $\mathbf{1} \mathbf{b}^{+}$. This indicated that the common stabilization mechanism for the covalently linked conventional MV species is applicable to the present urea-bridged MV species $\mathbf{1}^{+}$.

$$
(\mathbf{1})_{2} \underset{-e^{-}}{\stackrel{E_{1 / 2}}{\longrightarrow}} \mathbf{1}^{+} \stackrel{E_{1 / 2^{2+}}}{-e^{-}} \mathbf{1}^{2+}
$$

The highest occupied molecular orbitals (HOMOs) of the $\mathrm{NAr}_{3}$ components are hybridized, forming HOMO and HOMO-1 in both $\mathbf{1 a}$ and $\mathbf{1 b}$ as the antibonding and bonding combinations, respectively (Figure 3, top, and Supporting Information File 1, 


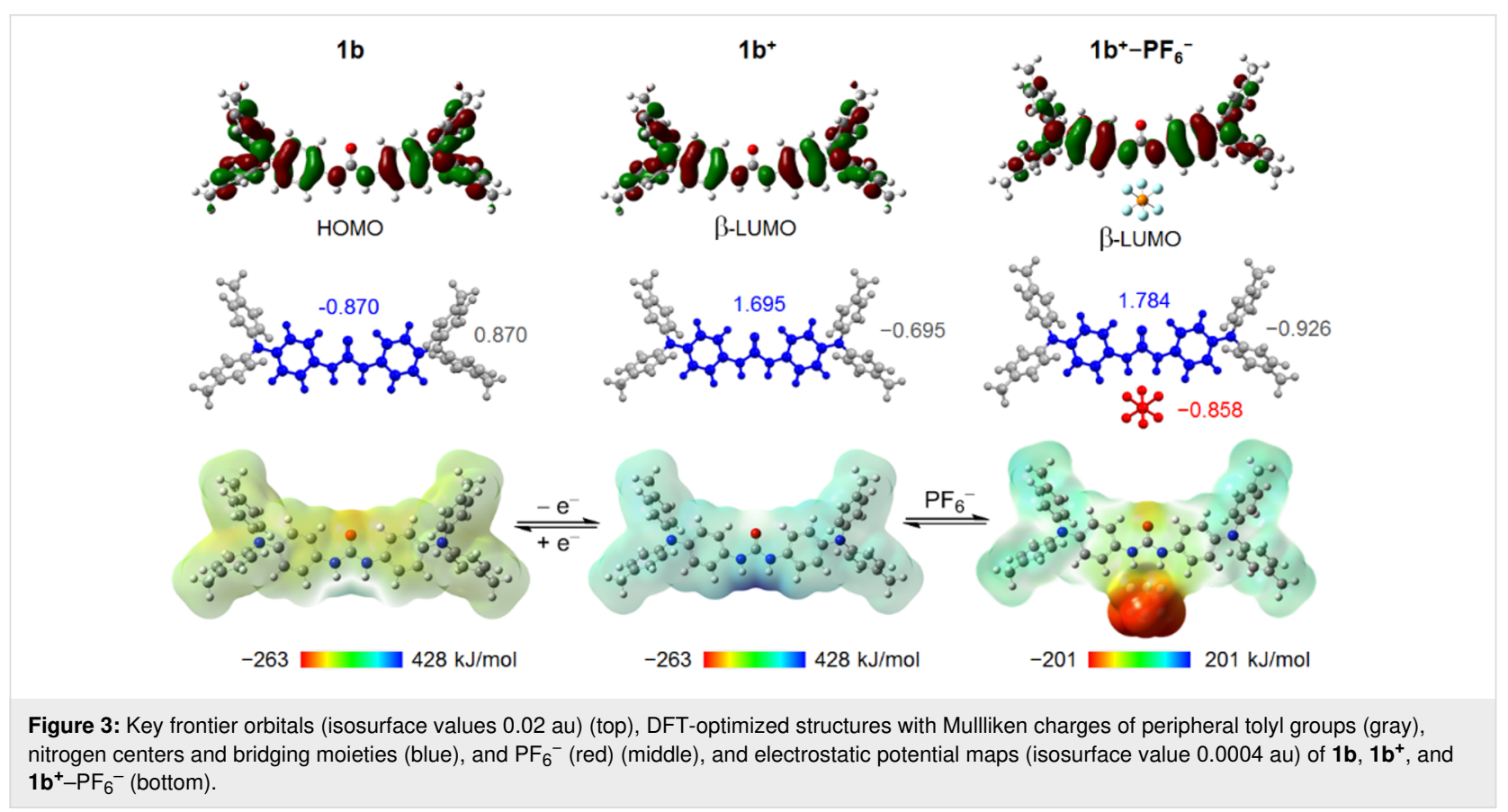

Figure S6). The differences between the HOMO and HOMO-1 energy levels were determined as $0.151 \mathrm{eV}$ for $\mathbf{1 a}$ and $0.155 \mathrm{eV}$ for $\mathbf{1 b}$. The larger splitting for $\mathbf{1 b}$ with respect to $\mathbf{1 a}$ is a common feature between DFT calculations and electrochemical investigations. This indicates that electronic interactions between the $\mathrm{NAr}_{3}$ units largely contribute to the experimentally proven thermodynamic stability of the MV state. Indeed, the energy level differences in the neutral precursors have been taken as $2 H_{\mathrm{AB}}$ of the $\mathrm{MV}$ species in previous reports on radical cations of bis $\left(\mathrm{NAr}_{3}\right)$ derivatives [11]. The HOMOs of $\mathbf{1 a}$ and 1b are distributed over both $\mathrm{NAr}_{3}$ units but not in the central carbonyl $\mathrm{C}=\mathrm{O}$ moiety of the ureylene bridge. This means that the $\pi$ orbital of the central $\mathrm{C}=\mathrm{O}$ moiety does not contribute to the $\pi$-conjugation in the HOMOs. Such HOMO properties would be understood by comparison with a well-known reference bis $\left(\mathrm{NAr}_{3}\right)$ derivative $\mathbf{M e O}-\mathbf{T P D}$, in which the $\mathrm{NAr}_{3}$ units are directly connected through a $\sigma$-bond [6]. MeO-TPD shows a larger energy difference between HOMO and HOMO-1 of $0.405 \mathrm{eV}$ (Supporting Information File 1, Figure S7). In addition, the HOMO of MeO-TPD is delocalized over the whole molecule through the $\sigma$-bond bridge.

More interestingly, the supporting electrolytes were observed to cause unusual effects on the electrochemical behavior of $\mathbf{1 b}$ (Figure 2, bottom). In the presence of $n-\mathrm{Bu}_{4} \mathrm{NBArF}_{4}$ (where $\mathrm{ArF}=3,5$-bis(trifluoromethyl)phenyl) as supporting electrolyte having a bulky counteranion, the potential splitting for $\mathbf{1 b}$ became less pronounced and decreased by $37 \mathrm{mV}$ compared to that with $n-\mathrm{Bu}_{4} \mathrm{NPF}_{6}$. A decreased potential splitting of $28 \mathrm{mV}$ was also observed for 1a. These observations corresponded to a 4.3-fold and 3.0-fold reduction in $K_{\mathrm{c}}$ for $\mathbf{1 b}$ and $\mathbf{1 a}$, respectively, and implies that the larger counteranion $\left(\mathrm{BArF}_{4}{ }^{-}\right)$destabilized the MV state $\mathbf{1}^{+}$. This stands in contrast to general MV compounds were $K_{\mathrm{c}}$ values in the presence of larger counteranions increase because they do not form strong ion-pairs with charged species, enhancing electrostatic interactions between redox components [46-52]. Thus, a different mechanism is proposed to explain the present effects of the supporting electrolytes in terms of counteranion size, as discussed in the next section.

\section{Characterization of $\mathbf{1}$ in the MV state}

DFT calculations were performed to obtain theoretical information about the MV state. The planarity of the urea moiety and the phenyl groups on both sides remained almost unchanged upon one-electron oxidation from $\mathbf{1}$ to $\mathbf{1}^{+}$(Supporting Information File 1, Figure S5). The enhanced acidity of the NH protons in $\mathbf{1} \mathbf{b}^{+}$, compared to that in $\mathbf{1 b}$, was well predicted by electrostatic potential maps. The positive regions (blue) were found around the two hydrogen atoms of the urea bridge in the electrostatic potential maps of $\mathbf{1 b}^{+}$(Figure 3, bottom). From these regions, $\mathbf{1 b}^{+}$can form electrostatic interactions with negatively charged species. Indeed, an optimized structure of a complex of $\mathbf{1 b}^{+}$and $\mathrm{PF}_{6}{ }^{-}$was obtained and featured an intermolecular $\mathrm{H}$-bonding between the $\mathrm{N}-\mathrm{H}$ proton and the $\mathrm{F}$ atom of hexafluorophosphate. Such $\mathrm{N}-\mathrm{H} \cdots \mathrm{F}$ hydrogen-bond formation was also reported for other urea derivatives with $\mathrm{PF}_{6}{ }^{-}$as counteranion in the solid state $[54,55]$. The $\mathrm{N} \cdots \mathrm{F}$ distance of $2.85 \AA$ in $\mathbf{1 b}^{+}-\mathrm{PF}_{6}{ }^{-}$is slightly longer than that observed in the crystal structure of a silver complex having a pyridyl urea ligand (2.67 
and $2.75 \AA$ ), primarily reflecting the absence of packing in the former. In the optimized structure of $\mathbf{1 a}^{+}-\mathrm{PF}_{6}{ }^{-}$, the $\mathrm{N}-\mathrm{H} \cdots \mathrm{F}$ hydrogen-bonding was comparable to that in $\mathbf{1 b}^{+}-\mathrm{PF}_{6}{ }^{-}$with regard to the atomic geometry and the N...F distances.

The increased acidity of $\mathbf{1}$ upon one-electron-oxidation enhances the binding strength to $\mathrm{PF}_{6}{ }^{-}$, suggesting an involvement of the $\mathbf{1}^{+}-\mathrm{PF}_{6}{ }^{-}$species during the electrochemical event of 1 described above. The comparison of DFT calculations between $\mathbf{1}^{+}$and $\mathbf{1}^{+}-\mathrm{PF}_{6}{ }^{-}$revealed that upon zwitterion formation, the bound $\mathrm{PF}_{6}{ }^{-}$can increase the electronic interactions between the $\mathrm{NAr}_{3}$ units. In the electrostatic potential maps of $\mathbf{1 b}^{+}-\mathrm{PF}_{6}{ }^{-}$ the light-green and red regions face each other through the ureylene bridge, indicating the polarized nature of the zwitterionic species (Figure 3, bottom). The Mulliken charges of the central blue moiety involving redox-active nitrogen centers are 0.089 larger for $\mathbf{1} \mathbf{b}^{+}-\mathrm{PF}_{6}{ }^{-}$than for $\mathbf{1} \mathbf{b}^{+}$(Figure 3, middle), meaning the larger positive charges are delocalized between the two nitrogen centers for $\mathbf{1 b}^{+}-\mathrm{PF}_{6}{ }^{-}$with the assistance of charge supply from the peripheral tolyl groups. In $\mathbf{1 b}^{+}-\mathrm{PF}_{6}{ }^{-}$, the Mulliken positive charge distributions agree well with the distributions of $\beta$-LUMO (lowest unoccupied molecular orbital) (Figure 3 , top). It should be noted that the $\beta$-LUMO of $\mathbf{1 b}^{+}-\mathrm{PF}_{6}{ }^{-}$is distributed in both the $\mathrm{NAr}_{3}$ units but not in the central $\mathrm{C}=\mathrm{O}$ moiety of the ureylene bridge, which is in the same situation as the HOMO of 1a. Upon binding with $\mathrm{PF}_{6}{ }^{-}$, the torsion of the central benzene rings in $\mathbf{1 b}^{+}$decreased by $1.31^{\circ}$, accompanied with a slight shortening of the $\mathrm{N} \cdots \mathrm{N}$ distances (Supporting Information File 1, Figure S5). These structural features contribute to an increase in the electronic coupling between the $\mathrm{NAr}_{3}$ units, thereby increasing the potential splitting seen in the electrochemical measurement. This is consistent with previous reports on bis $\left(\mathrm{NAr}_{3}\right)^{\bullet+}$ derivatives that showed a positive correlation between the electron-richness of the bridge and the electronic coupling strength between the $\mathrm{NAr}_{3}$ units [8]. In contrast, $\mathbf{1 b}^{+}$does not form a complex with the larger counteranion $\left(\mathrm{BArF}_{4}{ }^{-}\right)$because of steric hindrance but instead forms a conventional ion pair, resulting in a smaller potential splitting.

A polar solvent should interfere with the $\mathrm{N}-\mathrm{H} \cdots \mathrm{F}$ H-bonding in the present MV state. Indeed, in $\mathrm{MeCN} / \mathrm{CH}_{2} \mathrm{Cl}_{2}$ 9:1 containing $n$ - $\mathrm{Bu}_{4} \mathrm{NPF}_{6}$, 1a showed a $13 \mathrm{mV}$ smaller potential splitting than in $\mathrm{CH}_{2} \mathrm{Cl}_{2}$ containing $n-\mathrm{Bu}_{4} \mathrm{NPF}_{6}$ (Supporting Information File 1, Figure S9 and Table S3). This suggests a decrease in electronic interactions between the $\mathrm{NAr}_{3}$ units upon disrupting the H-bonds. The mixed solvent was selected because of the low solubility of $\mathbf{1 a}$ in $\mathrm{MeCN}$. In general, in a more polar solvent, electrostatic repulsions between the redox units become smaller, thus decreasing potential splitting [46-48]. This is the case with MeO-TPD in $\mathrm{CH}_{2} \mathrm{Cl}_{2}$ and $\mathrm{MeCN} / \mathrm{CH}_{2} \mathrm{Cl}_{2}$ 9:1 (Supporting Information File 1, Table S3). However, such electrostatic contribution to a change in the potential splitting should be smaller in case of compound 1a because of the separated

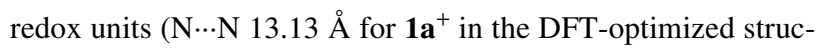
ture). Unfortunately, no investigations of solvent effects were performed with $\mathbf{1 b}$ due to the low solubility in polar solvents including $\mathrm{MeCN} / \mathrm{CH}_{2} \mathrm{Cl}_{2}$ mixed solvents.

To quantify the electronic interactions between the $\mathrm{NAr}_{3}$ units in the MV state, $\mathbf{1 b}$ was investigated in $\mathrm{CH}_{2} \mathrm{Cl}_{2} / n-\mathrm{Bu}_{4} \mathrm{NPF}_{6}$ by a spectroelectrochemical method. The medium was chosen to reduce the influence of disproportionation to the $\mathbf{1 b}$ and $\mathbf{1} \mathbf{b}^{\mathbf{2 +}}$ species. When the electrolysis of $\mathbf{1 b}$ was performed at $E_{1 / 2}{ }^{1}$, two new absorption bands were observed in this solution (Figure 4a). Based on its similarity to the reported $\mathrm{NAr}_{3}{ }^{\cdot+}$ derivatives [56], the first band at $760 \mathrm{~nm}$ derives from the $\pi-\pi^{*}$ transition of the $\mathrm{NAr}_{3}{ }^{\bullet+}$ moiety of $\mathbf{1 b}^{+}$[56]. However, the second band in the NIR region significantly differs in broad- (a)

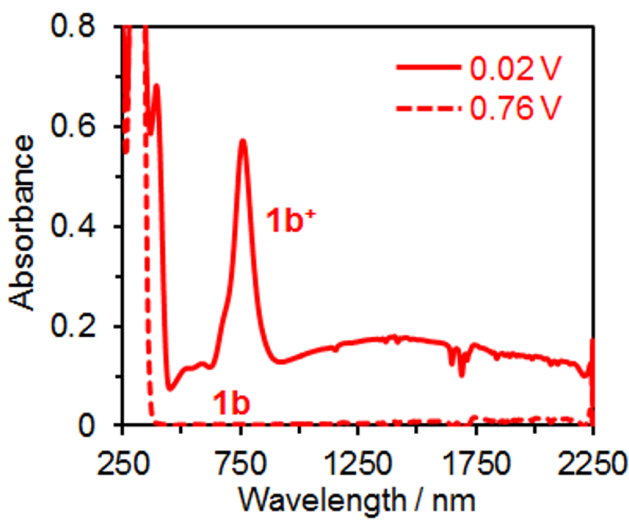

(b)

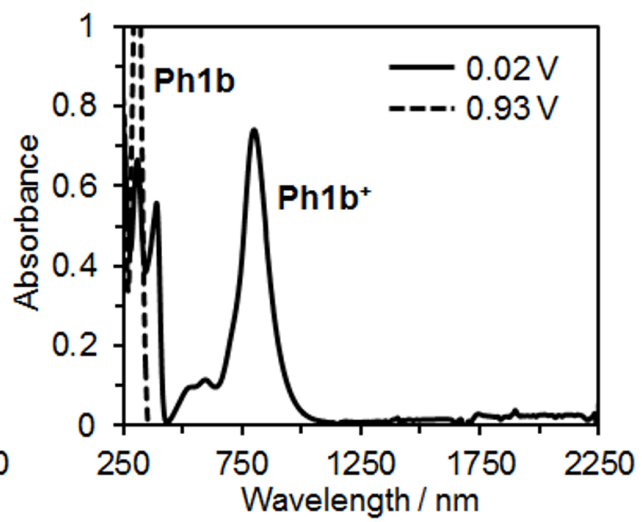

Figure 4: UV-vis-NIR spectral changes of $\mathrm{CH}_{2} \mathrm{Cl}_{2} / n-\mathrm{Bu}_{4} \mathrm{NPF}_{6}(0.10 \mathrm{M})$ solutions containing (a) $1 \mathrm{~b}\left(4.5 \times 10^{-4} \mathrm{M}\right)$ and (b) $\mathrm{Ph} 1 \mathrm{~b}\left(5.0 \times 10^{-4} \mathrm{M}\right)$ during the controlled potential electrolysis. Potentials in $\mathrm{mV}$ vs. $\mathrm{Fc}^{*+} / \mathrm{Fc}^{*}$. 
ness and intensity. Because any NIR absorption was not observed for the reference Ph1 $\mathbf{1} \mathbf{b}^{+}$(Figure 4b), this second band of $\mathbf{1 b}^{+}$is assigned to an IVCT transition from the $\mathrm{NAr}_{3}$ unit to the $\mathrm{NAr}_{3}{ }^{\cdot+}$ unit. Indeed, using time-dependent DFT (TD-DFT) calculations, an electronic transition from the $\beta$-HOMO to $\beta$-LUMO was predicted in the NIR region (at $1745 \mathrm{~nm}$ ) for $\mathbf{1 b}^{+}$ (Table S2 in Supporting Information File 1), which has an IVCT character corresponding to the experimentally observed one. The $\beta$-HOMO (194 $\beta$ ) and $\beta$-LUMO (195 $\beta$ ) for $\mathbf{1 b}^{+}$are distributed over both $\mathrm{NAr}_{3}$ units (Figure 3 and Figure S6 in Supporting Information File 1). When the electrolysis is performed at $E_{1 / 2}{ }^{2}+0.15 \mathrm{~V}$, the first band deriving from the $\pi-\pi^{*}$ transition of the $\mathrm{NAr}_{3}{ }^{\cdot+}$ moiety increased in intensity (Supporting Information File 1, Figure S10), reflecting the presence of two chromophores in the generated two-electron-oxidized species $\mathbf{1 b}^{\mathbf{2 +}}$. The generation of the dication agreed with the decrease in the IVCT intensity.

The IVCT band of $\mathbf{1} \mathbf{b}^{+}$was fitted using a Gaussian function (Figure 5) to obtain the spectroscopic parameters of energy $\left(v_{\max }\right)$, intensity $(\varepsilon)$, and bandwidth at the half-height $\left(\Delta v_{1 / 2}\right)$ (Table 2). An electronic coupling for $\mathbf{1} \mathbf{b}^{+}-\mathrm{PF}_{6}{ }^{-}$was calculated to be $H_{\mathrm{AB}}=810 \mathrm{~cm}^{-1}$ using Hush analysis $[1-5,19,20]$ with the three parameters. According to previous studies on bis $\left(\mathrm{NAr}_{3}\right)^{\bullet+}$ radical cations $[6,8]$, we adopted the $\mathrm{N} \cdots \mathrm{N}$ distance of the DFToptimized structure of $\mathbf{1 b}^{+}-\mathrm{PF}_{6}{ }^{-}(13.12 \AA)$ to determine $H_{\mathrm{AB}}$, although there is an uncertainty associated with the electron transfer distances in general organic MV systems [57,58]. As the IVCT bandwidth at half-height for $\mathbf{1 b}^{+}$is broader than the high-temperature limit $\left(47.94 \times\left(\Delta v_{1 / 2}\right)^{1 / 2}=4,120 \mathrm{~cm}^{-1}\right)$ [6], $\mathbf{1 b}^{+}$is regarded as a class II system.

The $H_{\mathrm{AB}}$ value for $\mathbf{1 b}^{+}$is by a factor of 4.9 greater than that reported for its ferrocenyl counterpart $\left(\mathbf{F C F}^{+}\right)$in the one-elec-

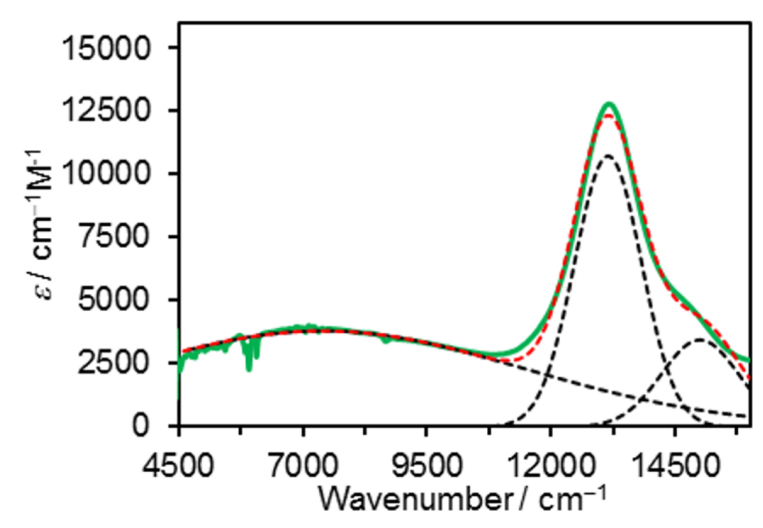

Figure 5: Vis-NIR spectra of $\mathbf{1 b}^{\mathbf{+}}$ (green line) obtained by bulk electrolysis, with Gaussian deconvolutions (black broken lines) and the sum (red broken line).
Table 2: IVCT band shape and electronic coupling factor of $\mathbf{1}^{+}$.

\begin{tabular}{llllll} 
& $\begin{array}{l}\mathrm{U}_{\max } \\
\left(\mathrm{cm}^{-1}\right)\end{array}$ & $\begin{array}{l}\varepsilon \\
\left(\mathrm{M}^{-1} \mathrm{~cm}^{-1}\right)\end{array}$ & $\begin{array}{l}\Delta \mathrm{U}_{1 / 2} \\
\left(\mathrm{~cm}^{-1}\right)\end{array}$ & $\begin{array}{l}H_{\mathrm{AB}}^{\mathrm{b}} \\
\left(\mathrm{cm}^{-1}\right)\end{array}$ & $\alpha^{\mathrm{c}}$ \\
\hline $\mathbf{1 a}^{+}$ & 8550 & 3050 & 7590 & 700 & 0.082 \\
$\mathbf{1 b}^{+}$ & 7400 & 3810 & 9590 & 820 & 0.110 \\
$\mathbf{F c F c}^{+d}$ & 8745 & 143 & 3323 & 165 & 0.019 \\
\hline
\end{tabular}

a $\mathrm{CH}_{2} \mathrm{Cl}_{2} / 0.1 \mathrm{M} n-\mathrm{Bu}_{4} \mathrm{NPF}_{6}$. ' Determined by the equation: $H_{\mathrm{AB}}=0.0206\left(\mathrm{U}_{\max } \varepsilon_{\max } \Delta \mathrm{U}_{1 / 2}\right)^{1 / 2} / r_{\mathrm{DA}}$ (where $r_{\mathrm{DA}}$ is the $\mathrm{N} \cdots \mathrm{N}$ distance between $\mathrm{NAr}_{3}$ moieties). ${ }^{c}$ Delocalization parameter $\alpha=H_{A B} / U_{\max } \cdot{ }^{d}$ In $\mathrm{CH}_{2} \mathrm{Cl}_{2}$ with $\mathrm{AgSbF}_{6}$ as reported in reference [42].

tron-oxidized form $\left(H_{\mathrm{AB}}=165 \mathrm{~cm}^{-1}\right)$ [42]. In conventional $\pi$-conjugated bis $\left(\mathrm{NAr}_{3}\right)$ derivatives [8], it was clearly demonstrated that electron-rich bridges increased $H_{\mathrm{AB}}$ values. In the previous and present urea-bridged MV systems, the involved counteranions can enhance the electron-richness of the bridge moieties through interactions with $\mathrm{NH}$ protons. Such interactions can contribute to the relatively large $H_{\mathrm{AB}}$ values seen in $\mathbf{1 b}^{+}$and $\mathbf{F} \mathbf{c F c} c^{+}$. The interaction parameter $(\alpha)$ is determined by the ratio of $H_{\mathrm{AB}}$ to $\lambda$ and quantifies the degree of delocalization [1-5]. Changing the redox-active components from ferrocene to $\mathrm{NAr}_{3}$ led to a 4.3 -fold increase in the $\alpha$ value. The degree of delocalization in the MV species can be understood in terms of the properties of the redox-active components; the positive charge of the ferrocenium moiety is accommodated largely on the $\mathrm{d}$ orbital, while that of the $\mathrm{NAr}_{3}{ }^{\cdot+}$ moiety is delocalized from the nitrogen center to the benzene ring adjacent to the urea bridge.

The MV species $\mathbf{1 a}^{+}$and the dication $\mathbf{1} \mathbf{a}^{\mathbf{2 +}}$ were also generated by the controlled-potential electrolysis and characterized by UV-vis-NIR spectroscopy (Figures S11, S12 in Supporting Information File 1 and Table 2). The replacement of the Me group at the para position by a OMe group decreased the $H_{\mathrm{AB}}$ values by $110 \mathrm{~cm}^{-1}$. Indeed, the Mulliken positive charges of the moieties covering the central bridge and nitrogen centers (blue regions) for $\mathbf{1 a}^{+}-\mathrm{PF}_{6}{ }^{-}$decreased by 0.142 compared to those for $\mathbf{1 b}^{+}-\mathrm{PF}_{6}{ }^{-}$(Figure S8 in Supporting Information File 1). This means that the peripheral electron-donating group of the $\mathrm{NAr}_{3}$ unit decreases the extent of delocalized positive charges. This is consistent with the previous reports on conventional $\pi$-conjugated bis $\left(\mathrm{NAr}_{3}\right)$ derivatives [8]. In their pioneering work on polyacetylene-bridged bis $\left(\mathrm{NAr}_{3}\right)$ derivatives, Lambert et al. demonstrated a negative linear correlation of $\ln \left(H_{\mathrm{AB}}\right)$ versus $n-1$, where $n$ is the bond number bridging the nitrogen centers of $\mathrm{NAr}_{3}$ moieties [6]. The $H_{\mathrm{AB}}$ value of $\mathbf{1 a}^{+}(n=12)$ was almost comparable to that of a polyacetylenebridged counterpart $\left(H_{\mathrm{AB}}=710 \mathrm{~cm}^{-1}\right.$ with $\left.n=13\right)$. We found that the present urea bridge can maintain electronic coupling in 
terms of the $\mathrm{N} \cdots \mathrm{N}$ distances between the $\mathrm{NAr}_{3}$ moieties with a small decrease of $H_{\mathrm{AB}}$ values.

\section{Conclusion}

A new series of urea-bridged bis $\left(\mathrm{NAr}_{3}\right)$ derivatives was electrochemically characterized. This study represents the first example of ionic MV species whose thermodynamic stability was enhanced more by smaller counterions than by larger counterions. This was achieved by introduction of a urea bridge and subsequent $\mathrm{H}$ bonding with counteranions. The resultant zwitterionic MV species was well modeled by DFT calculations. Through the spectroelectrochemical method, we confirmed that the urea bridge can maintain electronic coupling between the $\mathrm{NAr}_{3}$ moieties in the MV cations. These findings provide new insights into controlling MV characteristics and fabricating sophisticated molecular devices through supramolecular methods.

\section{Experimental}

\section{Materials and general measurements}

All solvents and chemicals of reagent grade were used without purification except tetra- $n$-butylammonium phosphate $\left(n-\mathrm{Bu}_{4} \mathrm{NPF}_{6}\right)$, which was recrystallized from methanol. 4-Aminotriphenylamine [59], 4,4'-dimethoxy-4' '-nitrotriphenylamine [38], 4,4'-dimethyl-4' '-nitrotriphenylamine [60], and $n-\mathrm{Bu}_{4} \mathrm{NBArF}_{4}$ [61] were synthesized as described in the literature. A JASCO V-670 spectrometer was used for UV-vis-NIR measurements at room temperature. The ${ }^{1} \mathrm{H}$ NMR spectra were recorded using a JEOL JNM-ECP400 spectrometer with tetramethylsilane (TMS) as internal standard ( 0 ppm). EIMS measurements were performed using a JEOL JMS-700 MStation spectrometer.

\section{Synthesis and characterization of com- pounds \\ Synthesis of 1a}

The mixture of 4,4'-dimethoxy-4', -nitrotriphenylamine $(0.351 \mathrm{~g}, 1.00 \mathrm{mmol})$ and $\mathrm{Pd} / \mathrm{C}(0.0145 \mathrm{~g})$ was refluxed in dry ethanol $(10 \mathrm{~mL})$ for $1 \mathrm{~h}$. After dropwise addition of hydrazine monohydrate $(0.30 \mathrm{~mL})$, the reaction mixture was refluxed overnight. After filtration of $\mathrm{Pd} / \mathrm{C}$ and concentrating the filtrate to dryness, the resulting white solid $(0.320 \mathrm{~g})$ was identified as 4-amino-4',4' '-dimethoxytriphenylamine by NMR comparison to reported data [62] which was used in the next step without further purification. To a solution of triphosgene $(0.148 \mathrm{~g}$, $0.500 \mathrm{mmol}$ ) in $15 \mathrm{~mL}$ of dry dichloromethane a solution of the crude product of 4-amino-4',4' '-dimethoxytriphenylamine $(0.32 \mathrm{~g})$ and $0.28 \mathrm{~mL}$ of triethylamine in dry dichloromethane $(15 \mathrm{~mL})$ was added at $0{ }^{\circ} \mathrm{C}$. After $10 \mathrm{~min}$ of stirring, $2.5 \mathrm{~mL}$ of dry pyridine were added and the mixture heated at $50{ }^{\circ} \mathrm{C}$ overnight. The reaction mixture was filtrated and concentrated to dryness. The resulting solid was dissolved in ethyl acetate and washed with water. After drying the organic layer over $\mathrm{Na}_{2} \mathrm{SO}_{4}$, the solution was concentrated to dryness. Compound 1a was isolated by column chromatography on silica gel using ethyl acetate $/ n$-hexane 1:1 as the eluent. Yield: $0.043 \mathrm{~g}(13 \%)$. ${ }^{1} \mathrm{H}$ NMR (400 MHz, DMSO- $\left.d_{6}, \mathrm{ppm}\right) \delta 3.71\left(\mathrm{~s}, 12 \mathrm{H},-\mathrm{CH}_{\underline{3}}\right)$, $6.80(\mathrm{~m}, 4 \mathrm{H},-\mathrm{NCC}(H) \mathrm{C}(\mathrm{H}) \mathrm{CN}(\mathrm{H})-), 6.85,6.90(\mathrm{~m}, 16 \mathrm{H}$, $-\mathrm{OCC}(H) \mathrm{C}(H) \mathrm{CN}-), 7.28(\mathrm{~m}, 4 \mathrm{H},-\mathrm{NCC}(\mathrm{H}) \mathrm{C}(H) \mathrm{CN}(\mathrm{H})-), 8.44$ $(\mathrm{s}, 2 \mathrm{H},-\mathrm{NH}-)$; HREIMS $(\mathrm{m} / z):[\mathrm{M}+\mathrm{Na}]^{+}$calcd for $\mathrm{C}_{41} \mathrm{H}_{38} \mathrm{~N}_{4} \mathrm{NaO}_{5}, 689.27399$; found: 689.27404 .

\section{Synthesis of $\mathbf{1 b}$}

Following a similar procedure as described for 1a and starting from 4,4'-dimethyl-4', -nitrotriphenylamine (0.637 g, $2.00 \mathrm{mmol}$ ), the target compound was synthesized and purified. Yield: $0.165 \mathrm{~g}$ (27\%). ${ }^{1} \mathrm{H}$ NMR (400 MHz, DMSO- $\left.d_{6}, \mathrm{ppm}\right) \delta$ $2.23\left(\mathrm{~s}, 12 \mathrm{H},-\mathrm{CH}_{3}\right), 6.83(\mathrm{~m}, 8 \mathrm{H}), 6.89(\mathrm{~m}, 4 \mathrm{H}$, $-\mathrm{NCC}(H) \mathrm{C}(\mathrm{H}) \mathrm{CN}(\mathrm{H})-), 7.05(\mathrm{~m}, 8 \mathrm{H}), 7.34(\mathrm{~m}, 4 \mathrm{H}$, - $\mathrm{NCC}(\mathrm{H}) \mathrm{C}(H) \mathrm{CN}(\mathrm{H})-), 8.54$ ( $\mathrm{s}, 2 \mathrm{H},-\mathrm{N} H$-); HREIMS $(\mathrm{m} / \mathrm{z})$ : $[\mathrm{M}+\mathrm{Na}]^{+}$calcd for $\mathrm{C}_{41} \mathrm{H}_{38} \mathrm{~N}_{4} \mathrm{NaO}, 625.29433$; found: 625.29533 .

\section{Synthesis of 1c}

To a solution of triphosgene $(0.296 \mathrm{~g}, 1.00 \mathrm{mmol})$ in $15 \mathrm{~mL}$ of dry dichloromethane a solution of the crude product of 4-aminotriphenylamine $(0.520 \mathrm{~g}, 2.00 \mathrm{mmol})$ and $0.70 \mathrm{~mL}$ of triethylamine in dry dichloromethane $(15 \mathrm{~mL})$ was added at $0{ }^{\circ} \mathrm{C}$. The reaction mixture was heated at $50{ }^{\circ} \mathrm{C}$ overnight and filtered. The filtrate was concentrated to dryness, the resulting solid was dissolved in chloroform and washed with water. After drying the organic layer over $\mathrm{Na}_{2} \mathrm{SO}_{4}$, the solution was concentrated to afford the target product 1c. Yield: $0.231 \mathrm{~g} \mathrm{(42 \% ).}{ }^{1} \mathrm{H}$ NMR $\left(400 \mathrm{MHz}, \mathrm{DMSO}-d_{6}, \mathrm{ppm}\right) \delta 6.96(\mathrm{~m}, 16 \mathrm{H}$, $-\mathrm{C}(H) \mathrm{C}(\mathrm{H}) \mathrm{C}(H) \mathrm{N}-,-\mathrm{NC}(H) \mathrm{C}(\mathrm{H}) \mathrm{CN}(\mathrm{H})-), 7.25(\mathrm{~m}, 8 \mathrm{H}$, $-\mathrm{C}(\mathrm{H}) \mathrm{C}(H) \mathrm{C}(\mathrm{H}) \mathrm{N}-), 7.41(\mathrm{~m}, 4 \mathrm{H},-\mathrm{NC}(\mathrm{H}) \mathrm{C}(H) \mathrm{CN}(\mathrm{H})-), 8.63$ $(\mathrm{s}, 2 \mathrm{H},-\mathrm{N} H-)$; HREIMS $(\mathrm{m} / \mathrm{z}):[\mathrm{M}+\mathrm{Na}]^{+}$calcd for $\mathrm{C}_{37} \mathrm{H}_{30} \mathrm{~N}_{4} \mathrm{NaO}$, 569.23173; found: 569.23174 .

\section{Synthesis of Ph1b}

The mixture of 4,4'-dimethyl-4"'-nitrotriphenylamine (0.318 g, $1.00 \mathrm{mmol})$ and $\mathrm{Pd} / \mathrm{C}(0.0145 \mathrm{~g})$ in dry ethanol $(10 \mathrm{~mL})$ was refluxed for $1 \mathrm{~h}$. After dropwise addition of hydrazine monohydrate $(0.30 \mathrm{~mL})$, the reaction mixture was refluxed overnight. After filtration and concentrating the filtrate to dryness, the resulting white solid $(0.320 \mathrm{~g})$ was identified as 4-amino-4',4', dimethyltriphenylamine by NMR [62] and used in the next step without further purification. To a solution of triphosgene $(0.296 \mathrm{~g}, 1.00 \mathrm{mmol})$ in $15 \mathrm{~mL}$ of dry dichloromethane at $0{ }^{\circ} \mathrm{C}$ a solution of aniline $(0.093 \mathrm{~g}, 1.00 \mathrm{mmol})$ and $0.56 \mathrm{~mL}$ of triethylamine in dry dichloromethane $(15 \mathrm{~mL})$ was added. After $10 \mathrm{~min}$ of stirring, $5.0 \mathrm{~mL}$ of dry pyridine were added followed 
by crude product of 4-amino-4',4"'-dimethyltriphenylamine $(0.288 \mathrm{~g})$. The resulting reaction mixture was heated at $50{ }^{\circ} \mathrm{C}$ overnight. After filtration the filtrate was concentrated, diluted with dichloromethane and washed with water. After drying the organic layer over $\mathrm{Na}_{2} \mathrm{SO}_{4}$, the solution was concentrated to dryness. Compound Ph1b was isolated by column chromatography on silica gel using ethyl acetate $/ n$-hexane $1: 1$. Yield: $0.086 \mathrm{~g} \mathrm{(21 \% ).}{ }^{1} \mathrm{H}$ NMR (400 MHz, DMSO- $\left.d_{6}, \mathrm{ppm}\right) \delta 2.23$ (s, $\left.6 \mathrm{H},-\mathrm{CH}_{3}\right), 6.83\left(\mathrm{~m}, 4 \mathrm{H},-\mathrm{NCC}(H) \mathrm{C}(H) \mathrm{C}\left(\mathrm{CH}_{3}\right)-\right), 6.90(\mathrm{~m}, 2 \mathrm{H}$, $-\mathrm{N}(\mathrm{H}) \mathrm{CC}(\mathrm{H}) \mathrm{C}(H) \mathrm{CN}-), 6.94(\mathrm{~m}, 1 \mathrm{H},-\mathrm{C}(H) \mathrm{C}(\mathrm{H}) \mathrm{C}(\mathrm{H}) \mathrm{CN}-)$, $7.05\left(\mathrm{~m}, 4 \mathrm{H},-\mathrm{NCC}(H) \mathrm{C}(H) \mathrm{C}\left(\mathrm{CH}_{3}\right)-\right), 7.26(\mathrm{~m}, 2 \mathrm{H}$, $-\mathrm{C}(\mathrm{H}) \mathrm{C}(H) \mathrm{C}(\mathrm{H}) \mathrm{CN}-), 7.35,7.43(\mathrm{~m}, 4 \mathrm{H},-\mathrm{C}(\mathrm{H}) \mathrm{C}(\mathrm{H}) \mathrm{C}(H) \mathrm{CN}-$, - $\mathrm{N}(\mathrm{H}) \mathrm{CC}(H) \mathrm{C}(\mathrm{H}) \mathrm{CN}-), 8.58,8.59$ (s, 2H, -NH-); HREIMS $(m / z):[\mathrm{M}+\mathrm{Na}]^{+}$calcd for $\mathrm{C}_{27} \mathrm{H}_{25} \mathrm{~N}_{3} \mathrm{NaO}, 430.18953$; found: 430.18889 .

\section{DFT calculations}

The DFT calculations were performed using the Gaussian09 software [63]. The three-parameterized Becke-Lee-Yang-Parr (B3LYP) hybrid exchange-correlation functional [64] was selected using the 6-31G(d) basis set for $\mathbf{1 a}$ and $\mathbf{1 b}$ with a restricted method and using the $6-311++\mathrm{G}(\mathrm{d}, \mathrm{p})$ basis set for the MV species with an unrestricted method. Vibrational frequencies were calculated to check the stability of the optimized structures and confirm that there are no imaginary frequencies. The TD-DFT calculations were also performed to predict electronic transitions with energies and oscillator strengths to obtain insight into UV-vis-NIR spectral data.

\section{Electrochemical investigations}

The electrochemical behavior was investigated using a BAS electrochemical analyzer (Bioanalytical Systems Inc, West Lafayette, IN, USA) with a three-electrode system composed of a platinum wire (1.6 mm diameter) counter electrode, a glassy carbon working electrode ( $3.0 \mathrm{~mm}$ diameter), and a $\mathrm{Ag} / \mathrm{AgCl}$ (3.0 M NaCl) reference electrode in $\mathrm{CH}_{2} \mathrm{Cl}_{2}$ solutions $(1.0 \mathrm{mM}$ ) of the target compound containing $0.1 \mathrm{M} n-\mathrm{Bu}_{4} \mathrm{NPF}_{6}$. Additional experiments were carried out in the presence of decamethylferrocene $\left(\mathrm{Fc}^{*}\right)$. The potentials versus the $\mathrm{Fc}^{+} / \mathrm{Fc}$ couple (where $\mathrm{Fc}=$ ferrocene) are also included in Table S4 (Supporting Information File 1), which are based on an independent experiment containing $\mathrm{Fc}$ and $\mathrm{Fc}^{*}$.

\section{Supporting Information}

\section{Supporting Information File 1}

Copies of ${ }^{1} \mathrm{H}$ NMR spectra of new compounds, DFT

calculation data, and electrochemical data.

[https://www.beilstein-journals.org/bjoc/content/

supplementary/1860-5397-15-220-S1.pdf]

\section{Acknowledgements}

This work was supported in part by JSPS KAKENHI 18K04890 and JP16H06514 in Coordination Asymmetry, as well as by Hitachi Metals Materials Science Foundation and Research Foundation for the Electrotechnology of Chubu. AS thanks the Ministry of Science and Higher Education of the Russian Federation (State assignment no. 4.1774.2017/4.6).

\section{ORCID ${ }^{\circledR} \mathrm{iDs}$}

Keishiro Tahara - https://orcid.org/0000-0003-0732-3921

\section{References}

1. Demadis, K. D.; Hartshorn, C. M.; Meyer, T. J. Chem. Rev. 2001, 101, 2655-2686. doi:10.1021/cr990413m

2. Brunschwig, B. S.; Creutz, C.; Sutin, N. Chem. Soc. Rev. 2002, 31 , 168-184. doi:10.1039/b008034i

3. D’Alessandro, D. M.; Keene, F. R. Chem. Soc. Rev. 2006, 35, 424-440. doi:10.1039/b514590m

4. D'Alessandro, D. M.; Keene, F. R. Chem. Rev. 2006, 106, 2270-2298. doi:10.1021/cr050010o

5. Aguirre-Etcheverry, P.; O'Hare, D. Chem. Rev. 2010, 110, 4839-4864. doi:10.1021/cr9003852

6. Lambert, C.; Nöll, G. J. Am. Chem. Soc. 1999, 121, 8434-8442. doi:10.1021/ja991264s

7. Heckmann, A.; Amthor, S.; Lambert, C. Chem. Commun. 2006, 2959-2961. doi:10.1039/b604603g

8. Barlow, S.; Risko, C.; Odom, S. A.; Zheng, S.; Coropceanu, V.; Beverina, L.; Brédas, J.-L.; Marder, S. R. J. Am. Chem. Soc. 2012, 134, 10146-10155. doi:10.1021/ja3023048

9. Low, P. J.; Paterson, M. A. J.; Puschmann, H.; Goeta, A. E.; Howard, J. A. K.; Lambert, C.; Cherryman, J. C.; Tackley, D. R.; Leeming, S.; Brown, B. Chem. - Eur. J. 2004, 10, 83-91. doi:10.1002/chem.200305200

10. Uebe, M.; Kazama, T.; Kurata, R.; Sakamaki, D.; Ito, A. Angew. Chem., Int. Ed. 2017, 56, 15712-15717. doi:10.1002/anie.201709874

11. Lambert, C.; Risko, C.; Coropceanu, V.; Schelter, J.; Amthor, S.; Gruhn, N. E.; Durivage, J. C.; Brédas, J.-L. J. Am. Chem. Soc. 2005, 127, 8508-8516. doi:10.1021/ja0512172

12. Reuter, L. G.; Bonn, A. G.; Stückl, A. C.; He, B.; Pati, P. B.; Zade, S. S.; Wenger, O. S. J. Phys. Chem. A 2012, 116, 7345-7352. doi:10.1021/jp303989t

13. Schmidt, H. C.; Spulber, M.; Neuburger, M.; Palivan, C. G.; Meuwly, M.; Wenger, O. S. J. Org. Chem. 2016, 81, 595-602. doi:10.1021/acs.joc.5b02427

14. Shen, J.-J.; Shao, J.-Y.; Zhu, X.; Zhong, Y.-W. Org. Lett. 2016, 18, 256-259. doi:10.1021/acs.orglett.5b03408

15. Burrezo, P. M.; Lin, N.-T.; Nakabayashi, K.; Ohkoshi, S.-i.; Calzado, E. M.; Boj, P. G.; Díaz García, M. A.; Franco, C.; Rovira, C.; Veciana, J.; Moos, M.; Lambert, C.; López Navarrete, J. T.; Tsuji, H.; Nakamura, E.; Casado, J. Angew. Chem., Int. Ed. 2017, 56, 2898-2902. doi:10.1002/anie.201610921

16. Schäfer, J.; Holzapfel, M.; Mladenova, B.; Kattnig, D.; Krummenacher, I.; Braunschweig, H.; Grampp, G.; Lambert, C. J. Am. Chem. Soc. 2017, 139, 6200-6209. doi:10.1021/jacs.7b01650

17. Zhang, Y.-M.; Wu, S.-H.; Yao, C.-J.; Nie, H.-J.; Zhong, Y.-W. Inorg. Chem. 2012, 51, 11387-11395. doi:10.1021/ic301004e 
18. Tahara, K.; Koyama, H.; Fujitsuka, M.; Tokunaga, K.; Lei, X.; Majima, T.; Kikuchi, J.-I.; Ozawa, Y.; Abe, M. J. Org. Chem. 2019, 84, 8910-8920. doi:10.1021/acs.joc.9b00836

19. Hankache, J.; Wenger, O. S. Chem. Rev. 2011, 111, 5138-5178. doi:10.1021/cr100441k

20. Heckmann, A.; Lambert, C. Angew. Chem., Int. Ed. 2012, 51, 326-392. doi:10.1002/anie.201100944

21. He, B.; Wenger, O. S. J. Am. Chem. Soc. 2011, 133, 17027-17036. doi:10.1021/ja207025x

22. Wenger, O. S. Chem. Soc. Rev. 2012, 41, 3772-3779. doi:10.1039/c2cs15339d

23. Cooke, G.; Rotello, V. M. Chem. Soc. Rev. 2002, 31, 275-286. doi:10.1039/b103906g

24. Bu, J.; Lilienthal, N. D.; Woods, J. E.; Nohrden, C. E.; Hoang, K. T.; Truong, D.; Smith, D. K. J. Am. Chem. Soc. 2005, 127, 6423-6429. doi:10.1021/ja0462272

25. Woods, J. E.; Ge, Y.; Smith, D. K. J. Am. Chem. Soc. 2008, 130, 10070-10071. doi:10.1021/ja803453e

26. Clare, J. P.; Statnikov, A.; Lynch, V.; Sargent, A. L.; Sibert, J. W. J. Org. Chem. 2009, 74, 6637-6646. doi:10.1021/jo9011392

27. Amendola, V.; Fabbrizzi, L.; Mosca, L. Chem. Soc. Rev. 2010, 39 , 3889-3915. doi:10.1039/b822552b

28. Li, A.-F.; Wang, J.-H.; Wang, F.; Jiang, Y.-B. Chem. Soc. Rev. 2010, 39, 3729-3745. doi:10.1039/b926160p

29. Dydio, P.; Lichosyt, D.; Jurczak, J. Chem. Soc. Rev. 2011, 40 , 2971-2985. doi:10.1039/c1cs15006e

30. Li, Y.; Park, T.; Quansah, J. K.; Zimmerman, S. C. J. Am. Chem. Soc. 2011, 133, 17118-17121. doi:10.1021/ja2069278

31. Clare, L. A.; Pham, A. T.; Magdaleno, F.; Acosta, J.; Woods, J. E.; Cooksy, A. L.; Smith, D. K. J. Am. Chem. Soc. 2013, 135, 18930-18941. doi:10.1021/ja410061x

32. Tamashiro, B. T.; Cedano, M. R.; Pham, A. T.; Smith, D. K. J. Phys. Chem. C 2015, 119, 12865-12874. doi:10.1021/acs.jpcc.5b03357

33. Clare, L. A.; Smith, D. K. Chem. Commun. 2016, 52, 7253-7256. doi:10.1039/c6cc03365b

34. Cedano, M. R.; Smith, D. K. J. Org. Chem. 2018, 83, 11595-11603. doi:10.1021/acs.joc.8b01570

35. Tadokoro, M.; Inoue, T.; Tamaki, S.; Fujii, K.; Isogai, K.; Nakazawa, H.; Takeda, S.; Isobe, K.; Koga, N.; Ichimura, A.; Nakasuji, K. Angew. Chem., Int. Ed. 2007, 46, 5938-5942. doi:10.1002/anie.200701277

36. Wilkinson, L. A.; McNeill, L.; Meijer, A. J. H. M.; Patmore, N. J. J. Am. Chem. Soc. 2013, 135, 1723-1726. doi:10.1021/ja312176x

37. Wilkinson, L. A.; McNeill, L.; Scattergood, P. A.; Patmore, N. J. Inorg. Chem. 2013, 52, 9683-9691. doi:10.1021/ic401555g

38. Tahara, K.; Nakakita, T.; Katao, S.; Kikuchi, J.-i. Chem. Commun. 2014, 50, 15071-15074. doi:10.1039/c4cc06779g

39. Jin-Long; Matsuda, Y.; Uemura, K.; Ebihara, M. Inorg. Chem. 2015, 54, 2331-2338. doi:10.1021/ic502953b

40. Tadokoro, M.; Hosoda, H.; Inoue, T.; Murayama, A.; Noguchi, K.; lioka, A.; Nishimura, R.; Itoh, M.; Sugaya, T.; Kamebuchi, H.; Haga, M.-a. Inorg. Chem. 2017, 56, 8513-8526. doi:10.1021/acs.inorgchem.7b01256

41. Mahmoud, K.; Long, Y.-T.; Schatte, G.; Kraatz, H.-B. J. Organomet. Chem. 2004, 689, 2250-2255. doi:10.1016/j.jorganchem.2004.04.016

42. Siebler, D.; Förster, C.; Gasi, T.; Heinze, K. Organometallics 2011, 30 , 313-327. doi:10.1021/om1010808
43. Gong, Z.-L.; Deng, L.-Y.; Zhong, Y.-W.; Yao, J. Phys. Chem. Chem. Phys. 2017, 19, 8902-8907. doi:10.1039/c6cp08019g

44. Gong, Z.-L.; Zhong, Y.-W.; Yao, J. Chem. - Eur. J. 2015, 21, 1554-1566. doi:10.1002/chem.201405332

45. Corbin, P. S.; Zimmerman, S. C.; Thiessen, P. A.; Hawryluk, N. A.; Murray, T. J. J. Am. Chem. Soc. 2001, 123, 10475-10488. doi:10.1021/ja010638q

46. Hildebrandt, A.; Lang, H. Organometallics 2013, 32, 5640-5653. doi:10.1021/om400453m

47. Winter, R. F. Organometallics 2014, 33, 4517-4536. doi:10.1021/om500029x

48. Diallo, A. K.; Absalon, C.; Ruiz, J.; Astruc, D. J. Am. Chem. Soc. 2011, 133, 629-641. doi:10.1021/ja109380u

49. Tahara, K.; Terashita, N.; Akita, T.; Katao, S.; Kikuchi, J.-i.; Tokunaga, K. Organometallics 2015, 34, 299-308. doi:10.1021/om501129a

50. Hildebrandt, A.; Miesel, D.; Lang, H. Coord. Chem. Rev. 2018, 371 , 56-66. doi:10.1016/j.ccr.2018.05.017

51. Tahara, K.; Akita, T.; Katao, S.; Tokunaga, K.; Kikuchi, J.-i. Dalton Trans. 2014, 43, 9579-9585. doi:10.1039/c4dt00988f

52. Tahara, K.; Akita, T.; Katao, S.; Kikuchi, J.-i. Dalton Trans. 2014, 43, 1368-1379. doi:10.1039/c3dt52503a

53. Bender, T. P.; Graham, J. F.; Duff, J. M. Chem. Mater. 2001, 13, 4105-4111. doi:10.1021/cm010281p

54. Custelcean, R. Chem. Commun. 2008, 295-307. doi:10.1039/b708921j

55. Blondeau, P.; van der Lee, A.; Barboiu, M. Inorg. Chem. 2005, 44, 5649-5653. doi:10.1021/ic050278y

56. Sreenath, K.; Suneesh, C. V.; Ratheesh Kumar, V. K.; Gopidas, K. R. J. Org. Chem. 2008, 73, 3245-3251. doi:10.1021/jo800349n

57. Brunschwig, B. S.; Creutz, C.; Sutin, N. Coord. Chem. Rev. 1998, 177, 61-79. doi:10.1016/s0010-8545(98)00188-x

58. Kattnig, D. R.; Mladenova, B.; Grampp, G.; Kaiser, C.; Heckmann, A.; Lambert, C. J. Phys. Chem. C 2009, 113, 2983-2995. doi:10.1021/jp8107705

59. Lee, W.-Y.; Kurosawa, T.; Lin, S.-T.; Higashihara, T.; Ueda, M.; Chen, W.-C. Chem. Mater. 2011, 23, 4487-4497. doi:10.1021/cm201665g

60. Liu, X.; Zhang, S. Synlett 2011, 1137-1142. doi:10.1055/s-0030-1260534

61. Barrière, F.; Geiger, W. E. J. Am. Chem. Soc. 2006, 128, 3980-3989. doi:10.1021/ja058171x

62. Moulin, E.; Niess, F.; Maaloum, M.; Buhler, E.; Nyrkova, I.; Giuseppone, N. Angew. Chem., Int. Ed. 2010, 49, 6974-6978. doi:10.1002/anie.201001833

63. Gaussian 09, Revision A.1; Gaussian, Inc.: Wallingford, CT, U.S.A., 2009.

64. Becke, A. D. J. Chem. Phys. 1993, 98, 5648-5652. doi:10.1063/1.464913 


\section{License and Terms}

This is an Open Access article under the terms of the Creative Commons Attribution License (http://creativecommons.org/licenses/by/4.0). Please note that the reuse, redistribution and reproduction in particular requires that the authors and source are credited.

The license is subject to the Beilstein Journal of Organic Chemistry terms and conditions:

(https://www.beilstein-journals.org/bjoc)

The definitive version of this article is the electronic one which can be found at:

doi:10.3762/bjoc. 15.220 